\title{
PROFILE OF HOMELESS PEOPLE IN EMERGENCY DEPARTMENTS
}

\author{
ANNA M. BURAK ${ }^{1,2}$, ZOFIA WYSZKOWSKA ${ }^{3}$, ARIEL LIEBERT ${ }^{4}$, and MARIA KŁOPOCKA ${ }^{4}$ \\ ${ }^{1}$ Nicolaus Copernicus University in Toruń, Toruń, Poland \\ Collegium Medicum in Bydgoszcz, Department of Emergency Medicine \\ ${ }^{2}$ University Hospital No. 2 in Bydgoszcz, Bydgoszcz, Poland \\ Clinical Department of Emergency Medicine \\ ${ }^{3}$ University of Technology and Life Sciences in Bydgoszcz, Bydgoszcz, Poland \\ Department of Management \\ ${ }^{4}$ Nicolaus Copernicus University in Toruń, Toruń, Poland \\ Collegium Medicum in Bydgoszcz, Department of Gastroenterology and Nutritional Disorders
}

\begin{abstract}
Objectives: For homeless people, emergency departments (ED) are the place of medical care and satisfying physiological, safety and social needs. The treatment of the homeless in EDs is a common issue in many countries. The aim of study was to analyze selected parameters of health care to homeless people in EDs. The authors examined the frequency and the seasonality of admissions, their causes, stay duration, insurance status, and the type of radiological diagnostics performed. Material and Methods: A retrospective analysis of stays of homeless patients in 3 EDs in one of the largest cities in Poland in 2013-2015 was carried out. Patients were qualified to the population of homeless people based of their registering in ED. Data was obtained on the total number of homeless patients' stays in all 3 EDs, which amounted to 3133 . Results: During the 3 years of analysis: 1042 homeless individuals were identified staying 3133 times in EDs; $46.3 \%$ of the stays concerned uninsured homeless people; $31 \%$ were under influence of alcohol. On average, men used ED services 3 times, while women only twice. No significant seasonality of admissions was observed. Homeless people were admitted mainly for mental disorders and head injuries. Radiological tests were performed 1577 times, including $83 \%$ being CT scans. On average, women and those $>30$ stayed in EDs for the shortest time. The hospital wards admitted $9.3 \%$ of the patients. Conclusions: Almost half of homeless patients repeatedly use ED services, regardless of the season. A patient's stay typically lasts $6 \mathrm{~h}$. Half of them were uninsured. The main reasons for admission include mental and behavioral disorders, mostly due to alcohol use and head injuries. The primary radiological diagnostics used were CT scans. Int J Occup Med Environ Health. 2022;35(2):157-67
\end{abstract}

Key words:

homelessness, medical care, hospital emergency department, homeless patients in EDs, disease diagnoses, repeated admissions

\section{INTRODUCTION}

In 2019, the number of homeless people in Poland was estimated to be $30330,20 \%$ of whom were the homeless living outside facilities of aid institutions [1]. This number has been relatively constant over the last decade.
Numerous reports emphasize the problem of repetitive visits of the homeless to emergency departments (ED), which have become a place not only to provide medical care to these patients, but also to satisfy their basic needs: physiological, safety and social ones [2-5]. There are no

$\overline{\text { Received: March 13, 2021. Accepted: July 13 }}, 2021$.

Corresponding author: Anna Burak, University Hospital No. 2 in Bydgoszcz, Clinical Department of Emergency Medicine, Ujejskiego 75, 85-168 Bydgoszcz, Poland (e-mail: annaburak72@gmail.com). 
data available in this respect in Poland, although the issue of the health care and treatment of homeless people in EDs is a common problem in Polish hospitals. Authors of a few studies on a comprehensive approach to the health of homeless people in Poland emphasize the problem of both poor health condition and the need to provide integrated health care to this group of patients [6-8]. Health interventions taken for homeless people in EDs are only oneoff and do not solve the health problems of those patients. The aim of this study was to analyze selected medical parameters associated with the provision of health services to homeless people in EDs in Poland, including the multiplicity and seasonality of admissions, diagnosed diseases, length of stay in the ED, radiological diagnostics performed, and the scale of services provided to uninsured patients.

\section{MATERIAL AND METHODS}

A retrospective analysis of stays of homeless patients in 3 EDs in one of the largest cities in Poland in 2013-2015 was carried out. Patients were qualified to the population of homeless people based of their registering in ED records according to 1 of the following 3 criteria: the definition of a homeless person applicable in Poland, confirmation of the homelessness status obtained from the patient and, in case of patients with a limited logical contact, recognition of the person as a homeless one on the basis of external factors indicating the homelessness of the patient - hygienic condition, degree of scruffiness and the place from where the patient was taken by the emergency medical team. Data was obtained on the total number of homeless patients' stays in all $3 \mathrm{EDs}$, which amounted to 3133.

The study obtained the approval of the Bioethics Committee KB 410/2016 of May 24, 2016.

\section{Statistical analysis}

The data was compiled using MS Excel and the Statistica v. 10 statistical software package. Descriptive statistics were presented: the arithmetic mean with standard deviation $(\mathrm{M} \pm \mathrm{SD})$. The relationship between the 2 variables was calculated using the Spearman's rank correlation coefficient. The differences between 2 groups as regards to 1 feature were assessed using the non-parametric MannWhitney U test, while the Kruskal-Wallis non-parametric test by ranks was used to compare multiple independent samples. The level of significance of $\mathrm{p}<0.050$ corresponding to the statistical data obtained was assumed as a statistically significant relationship between variables.

\section{Characteristics of the studied group of patients}

In the study population 1042 people were identified, including 943 homeless people with known identities and 99 whose identities were impossible to determine. Men constituted $85.2 \%$ of the study population. The age of men was $\mathrm{M} \pm \mathrm{SD} 48.2 \pm 12.7$ years and it was significantly higher than the age of women which was $\mathrm{M} \pm \mathrm{SD} 45.4 \pm 16.5$ years $(\mathrm{p}=0.029)$.

\section{RESULTS}

During the 3-year analysis period, 3133 stays of the population of 1042 homeless individuals were recorded in EDs, of which $46.3 \%$ concerned uninsured people $(\mathrm{N}=1450)$. Homeless women $(\mathrm{N}=154)$ were admitted 281 times while homeless men $(\mathrm{N}=888) 2852$ times. Women were significantly more likely to have insurance than men $(\mathrm{p}<0.0001)$. At the time of admission, 972 individuals (31\%) were under the influence of alcohol. The average blood alcohol concentration in the subjects was $2.97 \%$. On average, men used ED services 3 times $(\mathrm{M} \pm \mathrm{SD}$ $3.21 \pm 5.5)$, while women twice $(\mathrm{M} \pm \mathrm{SD} 1.82 \pm 1.6)$ and this was a statistically significant difference. In the study population, $7.1 \%(\mathrm{~N}=74)$ of patients were admitted 6-10 times and 5.8\% $(\mathrm{N}=57)$ were admitted $>10$ times, with some patients who were admitted $>30$ times: 31,44 , 50, 55 and 80 times, respectively. Spearman's test revealed no significant correlation between the age of subjects 
and the number of ED admissions $(r=0.008, N=865$, $\mathrm{p}=0.816$ ).

Months of admissions were assigned to calendar seasons: spring (March, April, May), summer (June, July, August), autumn (September, October, November), winter (December, January, February). The percentage of admitted patients in particular seasons differed slightly, but the differences were not statistically significant (Figure 1).

A total of 3826 codes of underlying diseases (Table 1) were identified in homeless patients based on the International Statistical Classification of Diseases and Related Health Problems ICD-10 [9]. The majority of diagnoses concerned categories S00-T98 and F00-F99 (63.8\%). Following the previous studies, the most frequent diagnoses in each of the main categories were listed [10]. No significant difference was found between men and women and the number of diagnoses in the major categories of ICD-10 $(\mathrm{p}=0.410)$.

For 9.3\% ( $=292)$ of patients, the stay in EDs ended with the admission to hospital wards. Most admissions were to internal medicine wards (38.7\%), with the remainder to orthopedic (14\%), surgical (13\%) neurosurgical (9.2\%), and neurological (8.2\%) wards. The main reasons for hospitalization were trauma, poisoning, and other specified effects of external factors (S00-T98, 42\%), cardiovascular diseases (I00-I99, 17\%), gastrointestinal diseases (K00-K93, 6.5\%) as well as skin and subcutaneous tissue (L00-L99, 4.7\%) diseases. Among the hospitalized homeless individuals in the previously mentioned hospital wards, $27.4 \%(\mathrm{~N}=80)$ were under the influence of alcohol at the time of the admission, and 29.5\% $(\mathrm{N}=86)$ had no insurance.

Three people died in EDs (0.1\%). The deceased were male, with an average age of $\mathrm{M} \pm \mathrm{SD} 59.7 \pm 15.5$ years. The reason for admission of patients in EDs in 2 cases was the toxic effect of alcohol (T51), and hypothermia (T68) in 1 case. Patients underwent 1577 diagnostic radiological procedures, $83 \%$ of which were computed tomography (CT) scans. A total of $1306 \mathrm{CT}$ scans were performed in 510 pa-

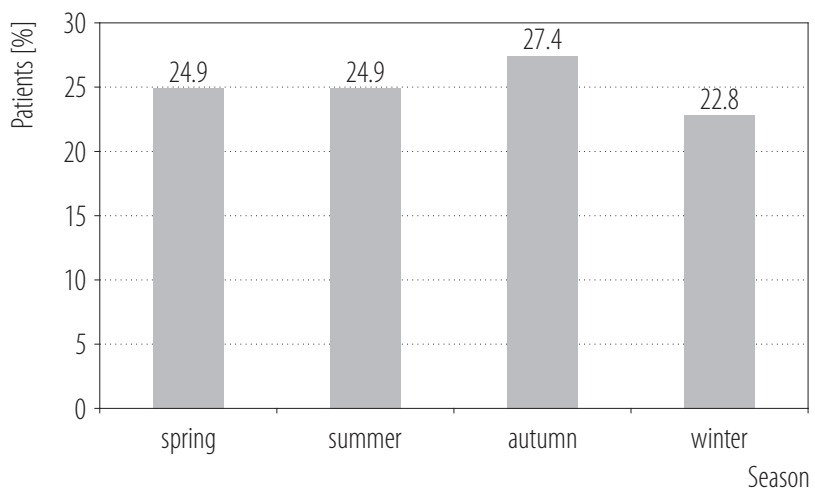

Figure 1. Homeless patients admissions to emergency departments (ED) by season in 3 EDs in one of the largest cities in Poland in 2013-2015

tients during the 3-year analysis period, of which $75.9 \%$ $(\mathrm{N}=387)$ had $1-2$ examinations and $4.3 \%(\mathrm{~N}=22)$ had 10-26 CT scans. Head CT was the most commonly performed scan, which accounted for $87.1 \%$ of all CT scans. Patients stayed in EDs for an average of $6 \pm 6.7 \mathrm{~h}$. The shortest stay in ED lasted $1 \mathrm{~h}$, and the longest lasted $123 \mathrm{~h}$. Women and patients $<30$ years of age stayed in EDs for the shortest time on average. The average length of stay of men was significantly longer $(\mathrm{p}<0.0001)$ than for women. The difference in length of stay between patients in individual age groups was significant $(\mathrm{p}<0.0001)$. There was a slight statistically significant correlation between patients of individual age groups and mean duration of stay in EDs $(r=0.093, N=2600, p<0.0001)$. Patients with unknown identities stayed in EDs for the longest time. Their mean length of stay was significantly longer $(\mathrm{p}<0.0001)$ than that of patients with identified personal data. The average length of stay of patients under the influence of alcohol was significantly longer $(\mathrm{p}<0.0001)$ than that of sober patients (Table 2).

\section{DISCUSSION}

This study is the first one in Poland to collect and analyze data on the stays of homeless patients in EDs. According to the Polish law, homeless person is one who does not live in a dwelling unit within the meaning of 
Table 1. The most frequently diagnosed diseases in a given disease category according to the International Statistical Classification of Diseases and Health Problems Revision 10 (ICD-10) in homeless patients admitted to emergency departments (ED) in 3 EDs in one of the largest cities in Poland in 2013-2015

\begin{tabular}{|c|c|c|c|}
\hline \multirow[t]{2}{*}{ ICD-10 } & \multicolumn{2}{|c|}{$\begin{array}{l}\text { Participants } \\
(\mathrm{N}=3826)\end{array}$} & \multirow[t]{2}{*}{ Diagnosis of diseases } \\
\hline & $\mathrm{n}$ & $\%$ & \\
\hline A00-B99 Infectious and parasitic diseases & 13 & 0.3 & tuberculosis $(N=4)$, sepsis $(N=2)$, scabies $(N=2)$, pediculosis $(N=1)$ \\
\hline C00-D48 Neoplasms & 14 & 0.4 & head cancer $(\mathrm{N}=3)$, bladder cancer $(\mathrm{N}=2)$ \\
\hline $\begin{array}{l}\text { D50-D89 Diseases of the blood and blood-forming } \\
\text { tissues }\end{array}$ & 7 & 0.2 & anemias $(\mathrm{N}=3)$ \\
\hline E00-E90 Endocrine, nutritional and metabolic diseases & 49 & 1.3 & diabetes mellitus $(\mathrm{N}=41)$ \\
\hline F00-F99 Mental and behavioral disorders & 891 & 23.3 & $\begin{array}{l}\text { disorders caused by the use of alcohol }(N=600) \text {, disorders caused by } \\
\text { the use of psychoactive substances }(N=88) \text {, personality disorders }(N=52) \text {, } \\
\text { schizophrenia }(N=34) \text {, mild mental retardation }(N=20)\end{array}$ \\
\hline G00-G99 Diseases of the nervous system & 167 & 4.4 & epilepsy $(N=150)$ \\
\hline H00-H59 Diseases of the eye and adnexa & 19 & 0.5 & conjunctivitis $(N=8)$, senile cataract $(N=2)$ \\
\hline H60-H95 Diseases of the ear & 4 & 0.1 & acute otitis media ( $\mathrm{N}=2$ ) \\
\hline 100-199 Diseases of the circulatory system & 108 & 2.8 & $\begin{array}{l}\text { cerebral infarction }(N=16) \text {, heart failure }(N=13) \text {, cardiomyopathies }(N=9) \text {, } \\
\text { atrial fibrillation and flutter }(N=8) \text {, atherosclerosis }(N=8) \text {, circulatory } \\
\text { arrest }(N=7) \text {, myocardial infarction }(N=7)\end{array}$ \\
\hline J00-J99 Diseases of the respiratory system & 35 & 0.9 & pneumonia $(\mathrm{N}=13)$ \\
\hline K00-K93 Diseases of the digestive system & 46 & 1.2 & gastric ulcer $(N=6)$, alcoholic liver disease $(N=5)$, acute pancreatitis $(N=5)$ \\
\hline L00-L99 Diseases of the skin and subcutaneous tissue & 57 & 1.5 & $\begin{array}{l}\text { chronic ulcer of lower limb }(N=24) \text {, infections of the skin and subcutaneous } \\
\text { tissue }(N=14) \text {, cellulitis and acute lymphangitis }(N=10)\end{array}$ \\
\hline $\begin{array}{l}\text { M00-M99 Diseases of the musculoskeletal system } \\
\text { and connective tissue }\end{array}$ & 35 & 0.9 & osteoarthritis of knee $(\mathrm{N}=4)$, soft tissue disorders $(\mathrm{N}=4)$ \\
\hline N00-N99 Diseases of the genitourinary system & 35 & 0.9 & $\begin{array}{l}\text { disorders of urinary system }(N=6) \text {, kidney failure }(N=4) \text {, calculus of urinary } \\
\text { tract }(N=4) \text {, renal colic }(N=4)\end{array}$ \\
\hline 000-099 Pregnancy, childbirth and puerperium & 16 & 0.4 & pregnancy $(\mathrm{N}=5)$, diabetes mellitus in pregnancy $(\mathrm{N}=2)$ \\
\hline $\begin{array}{l}\text { R00-R99 Symptoms, signs and abnormal clinical } \\
\text { and laboratory findings, not elsewhere classified }\end{array}$ & 218 & 5.7 & $\begin{array}{l}\text { pain in throat and chest }(N=43) \text {, abdominal and pelvic pain }(N=54) \text {, illness } \\
\text { of unspecified origin }(N=31) \text {, syncope and collapse }(N=16)\end{array}$ \\
\hline $\begin{array}{l}\text { S00-T98 Injury, poisoning and certain other } \\
\text { consequences of external causes }\end{array}$ & 1550 & 40.5 & $\begin{array}{l}\text { superficial head injury }(N=446) \text {, toxic effect of alcohol }(N=301) \text {, open } \\
\text { wound of head }(N=172) \text {, fracture of lower leg }(N=51) \text {, fracture of skull } \\
\text { and facial bones }(N=48) \text {, injuries involving multiple body regions }(N=31) \text {, } \\
\text { intracranial injury }(N=26)\end{array}$ \\
\hline V01-Y98 External causes of morbidity and mortality & 268 & 7.0 & $\begin{array}{l}\text { fall }(N=91) \text {, evidence of alcohol involvement }(N=43) \text {, hit, strike or kick by } \\
\text { another person }(N=18)\end{array}$ \\
\hline $\begin{array}{l}\text { Z00-Z99 Factors influencing health status and contact } \\
\text { with health services }\end{array}$ & 294 & 7.7 & medical observation and evaluation for suspected diseases and conditions \\
\hline
\end{tabular}

the legal provisions on the protection of the rights of tenants and municipal residential resources and who is not registered for permanent residence, as defined in the pro- visions on the population records, as well as a person who does not live in a dwelling unit and registered for permanent residence in a place that is not suitable for dwelling. 
Table 2. Average duration of the of stay in emergency departments (ED), taking into account the variables in homeless patients admitted to emergency departments in 3 EDs in one of the largest cities in Poland in 2013-2015

\begin{tabular}{|c|c|c|c|c|c|c|}
\hline \multirow[t]{2}{*}{ Variable } & \multirow{2}{*}{$\begin{array}{c}\text { Participants } \\
(\mathrm{N}=2841) \\
{[\mathrm{n}]}\end{array}$} & \multicolumn{4}{|c|}{$\begin{array}{l}\text { Emergency department stay } \\
\text { [h] }\end{array}$} & \multirow[t]{2}{*}{$\mathrm{p}$} \\
\hline & & M & SD & $95 \% \mathrm{Cl}$ & Me & \\
\hline Gender & & & & & & $<0.0001$ \\
\hline female & 238 & 4.01 & 4.55 & $3.43-4.59$ & 3.0 & \\
\hline male & 2603 & 5.75 & 6.82 & $5.49-6.01$ & 3.0 & \\
\hline Age & & & & & & $<0.0001$ \\
\hline$\leq 30$ years & 335 & 4.59 & 4.99 & $4.06-5.13$ & 3.0 & \\
\hline $31-40$ years & 433 & 5.18 & 5.59 & $4.66-5.71$ & 3.0 & \\
\hline $41-50$ years & 671 & 5.56 & 7.84 & $4.96-6.15$ & 3.0 & \\
\hline $51-60$ years & 837 & 5.65 & 5.49 & $5.27-6.02$ & 3.0 & \\
\hline$>60$ years & 324 & 6.44 & 7.17 & $5.65-7.22$ & 4.0 & \\
\hline Patients with unknown identity & & & & & & $<0.0001$ \\
\hline no & 2742 & 5.48 & 6.34 & $5.25-5.72$ & 3.0 & \\
\hline yes & 99 & 8.88 & 12.57 & $6.37-11.39$ & 6.0 & \\
\hline Intoxication & & & & & & $<0.0001$ \\
\hline no & 1949 & 5.40 & 6.93 & $5.09-5.70$ & 3.0 & \\
\hline yes & 892 & 6.05 & 6.07 & $5.65-6.45$ & 4.0 & \\
\hline
\end{tabular}

Homeless patients admitted to EDs reflect the demographic characteristics of the general Polish homeless population, in which men are the vast majority, and the most numerous age group ranges 41-60 years [1]. That data coincides with that reported by other researchers $[3,11,12]$.

\section{Repeated admissions of homeless patients in EDs}

Researchers have indicated for many years that EDs are a substitute of the primary health care for homeless patients [4]. This applies in particular to non-institutionalized homeless people, who are significantly more likely to seek emergency care in EDs compared to homeless residents of institutional shelter facilities. In a study by Kushel et al. [5], nearly half of the homeless people who used ED assistance treated this place as their only available source of health care. According to the authors, access to comprehensive services provided by EDs is easy and available around the clock. The literature provides numerous reports of repeated stays of homeless patients in EDs $[5,11,13,14]$. In a study by Wang et al. [12], 76\% of admissions of homeless patients were considered medically unjustified, and two-thirds of those patients were uninsured. In the authors' own study, men were admitted an average of 3 times, while women 2 in the analyzed period, and this was a statistically significant difference. In an extreme case, the number of stays was even 80 . According to Little and Watson [4], the highest number of re-admissions takes place shortly after the previous discharge from ED or a hospital and applies to patients with injuries. The same opinion is held by Doran [3], who argues that discharging a homeless patient from ED to his/her place of residence, which is often an unknown location, is associated with an increased risk of readmission. 
Consideration should be given to how to minimize unjustified admissions to EDs and to reduce the probability of readmission. It seems reasonable to provide a homeless patient with the opportunity to contact a social worker each time. This would require closer cooperation between ED staff and a social worker, perhaps including re-organization of his or her working hours in hospitals.

\section{Seasonal nature of admissions}

This study did not reveal any clear trend in the seasonal nature of homeless patients' admissions to EDs. In the study by Hamming et al. [15], spring and fall were the periods with the highest while winter had the lowest number of admissions, but the differences in admission rates between the seasons, as in the authors' own research, were not significant. It is likely that during the winter months, especially during cold weather, more homeless people are willing to use shelters and night shelters. No trend in the seasonal nature of admissions is also confirmed by Brown et al. [16]. On the other hand, Yeniocak et al. [17] pointed out a clear seasonal variation in the number of admissions of injured homeless patients. The vast majority of admissions of such patients occurred during the summer months, which is associated by the author with the increased presence of homeless people on the streets and thus a greater likelihood of exposure to injury.

\section{Disease diagnoses in homeless patients}

Chronic diseases, multimorbidity, and often disability are the factors that contribute to the overall poor health of the homeless $[18,19]$. The authors point out that the reasons for admissions of homeless patients to EDs rarely include a sudden threat to their health or life. Two-thirds of all diagnoses in this study fell in 2 ICD-10 categories:

- F00-F99 - "mental and behavioral disorders," including largely "mental and behavioral disorders caused by alcohol use,"
- S00-T98 - "injury, poisoning and certain other consequences of external causes, including mainly superficial injury of head."

Diagnoses of injuries, mental disorders, and those related to the use of alcohol or other psychoactive substances were also most common in other studies [13,18-20]. In the study by Lombardi et al. [13], Injuries accounted for half of the diagnoses, while the authors emphasized the problem of addiction to alcohol or other substances, and the presence of mental disorders among homeless patients. The study by Azar et al. [2] seems to be very interesting in this context, as they found that patients with mental disorder diagnoses were more likely to be frequently admitted to EDs.

Other diagnoses were much less frequent in this study. There were 4 diagnoses of tuberculosis in the study group $(0.1 \%)$. This is not many for according to the interpretation of Beijer et al. [21] the tuberculosis may affect $0.2-7.7 \%$ of the homeless population. In a study by Hwang et al. [22], 35 cases of tuberculosis (1.06\%) were diagnosed among homeless patients in EDs over a 2-year period. Appleton et al. report that homeless people, as well as people addicted to alcohol, are among the highrisk groups for tuberculosis, and ED is a place where the chance of diagnosing the disease in these patient groups is higher [23]. Geyer et al. [24] stresses that it may be the only such place, which confirms the role of EDs as the primary health care provision place for the homeless. A chest radiograph performed in EDs in at-risk patients, combined with the symptoms found during physical examination, significantly increases the likelihood of earlier diagnosis of the disease $[23,24]$.

Interestingly, there was only 1 diagnosis of pediculosis (B85), 2 of scabies (B86), and not a single diagnosis of parasitic disease (B89) in the study group. However, this does not mean that these diseases do not occur in homeless patients. The problem of parasitic diseases, pediculosis, and scabies, as well as other skin diseases, including 
fungal infections, is common among homeless patients, especially for non-institutionalized ones [25]. The reasons why those conditions remain undiagnosed should be attributed to the lack of coding of these diseases as less important from the point of view of diagnosis in EDs, rather than to the failure to diagnose them during a physical examination. It is possible that a similar trend may also apply to other diagnoses.

There were 14 diagnoses $(0.4 \%)$ of cancer (C00-D48) in the study group. A similar percentage, $0.6 \%$ of diagnoses, was reported by Karaca in his study [20]. It is estimated that mortality due to cancer is twice as high in homeless individuals as in the general population [26]. The problem of neoplastic diseases and their early detection in homeless patients seems to be neglected not only in Poland. Chau et al. [27] emphasize the absence of preventive programs both for the charges of shelters and health institutions where homeless people are placed.

Pregnancy-related diagnoses accounted for an insignificant percentage $(0.4 \%)$ in the study; however, in the studies by American authors, pregnancy-related diagnoses concern one-fifth of homeless women [14]. Homeless women rarely use contraception. Many do not use contraception at all [28]. Homelessness, mental disorders associated with the use of alcohol and other substances, depressive episodes, personality disorders, and post-traumatic stress disorder are factors that may adversely affect the health of a pregnant woman and the proper prenatal development of the child and the appropriate care for the child after birth [29]. Therefore, it is important to diagnose the pregnancy as early as possible and to cover the pregnant woman with the social welfare system. The issue of contraceptive education is also important.

\section{Computed tomography scans}

Computed tomography (CT) scans are the primary radiological diagnostics in homeless patients in Polish hospitals. The percentage of CT scans performed was 5 times higher than other radiological examinations. One in 8 patients had $\geq 5$ CT scans during the analysis period. The examinations were performed at different facilities. It is interesting to note how many examinations could have been avoided if medical records of homeless persons and their treatment history had been available in individual EDs. This is not a solely economic issue, but also a problem of patient exposure to cumulative doses of ionizing radiation [30]. These results differ from those reported by Yeniocak et al. [17], where homeless patients admitted for trauma as well as for non-trauma-related reasons, had radiological examinations performed as standard. The percentage of CT scans performed was 3 times less than all X-ray examinations performed.

\section{Length of stay of homeless patients in EDs}

Discharging a homeless patient from a hospital is both an organizational and moral problem. Lack of the place of residence prevents medical transport to the indicated location. The most common practice is to wait until a patient is able to leave the ED on his/her own after being treated there. This is one of the reasons why the time of homeless patients' stays in EDs is longer than that of other patients admitted for the same reason [31].

Homeless patients stay in EDs for an average of $6 \mathrm{~h}$. The duration of the stay depends on the patients' gender, age and his or her sobriety or being under the influence of alcohol. The length of stay is significantly longer for men, patients $>60$ years of age, and patients under the influence of alcohol. In the younger homeless population, shorter duration of stay may result from potentially greater ability to move independently compared to homeless patients $>60$ years of age, who are more likely to have disabilities [32].

The findings of other researchers most often involve comparing the time spent by homeless patients in the ED with that of other patients. These differences are statisti- 
cally significant. In the study by Feral-Pierssens et al. [11] the average length of stay for homeless patients was $5 \mathrm{~h}$, i.e., almost 50\% longer than for other patients. Rodriguez et al. [31] point out that also other non-medical needs of a patient such as shelter, clothing, or food are also satisfied during his or her stay in the ED, which decreases the motivation to leave the ED. Situations when homeless patients spend a night in the ED despite already having completed diagnostic and therapeutic process are not rare [11]. Such problems occurs also in Polish medical institutions.

\section{The scale of medical services}

\section{provided to uninsured homeless people}

Emergency departments are obliged to provide medical aid to all persons experiencing sudden danger to their health or life. Medical services are obliged to provide aid also to uninsured people, including the homeless, despite the fact that from the economic point of view it exposes the hospital to financial loss. The issue is quite serious because, as the study results show, nearly half of homeless people admissions to EDs involve uninsured people, including significantly more men than women. The data coincides with the results reported by other researchers [13,20]. In Martell et al's study [33] covering the years 1988-1990, the percentage of uninsured homeless patients was even higher (64\%). This may suggest that the number of insured homeless people has increased over the years. According to Dębski [7], 65.2\% of the total homeless population in Poland have insurance, and the percentage of insured people staying in homeless shelters is even higher, reaching $85 \%$.

For uninsured patients, it is possible to initiate the procedure of insuring them. The main precondition for initiating the procedure is conducting a community interview with the patient by a social worker [34]. But the problem lies in an insufficient number of social workers employed in hospitals as well as lack of 24-hour availability of those workers. The optimal solution would be to employ such person e.g. as an emergency worker on call. This would increase the chances of implementing the insurance procedure before the patient leaves the ED, but would also allow more homeless patients to be covered by social assistance.

Many researchers provide evidence of poor health of homeless persons $[18,19]$, which was not reflected in this research. Only 9\% of homeless patients' stay in EDs ended with the admission to a hospital ward. Hospital emergency departments are focused on rescuing people in a life and health-threatening condition. These interventions are of emergency nature, one-off and such are undertaken with homeless patients. But this population first of all needs a comprehensive approach including broadly understood prevention. The failure to provide a systemic approach to the treatment of the homeless results in the real problem of homeless patients in EDs.

\section{Limitations of the study}

The limitation of the study consisted in the fact that the data was acquired from hospital emergency departments of 1 city in Poland. Attention should also be given to a potential misselection of the study group during patients registration. It may be assumed that ED employees, influenced by appearance stereotypes, do not always make sure if a patient was homeless. As a result, they might have incorrectly classified someone who does not belong to this group as a homeless person, or unintentionally excluded institutionalized homeless people whose appearance often differs from the typical image of a homeless person.

The results of this study are pioneering and constitute a comprehensive analysis of the stays of homeless patients in EDs in Poland. At the same time they show systemic deficiencies in the health care of homeless patients in Poland, and following the literature analysis, also in other European countries. 


\section{CONCLUSIONS}

Almost half of the homeless patients population repeatedly use the services provided in EDs, regardless of the season while the average duration of a stay in ED for the group of homeless patients subjected to the study is $6 \mathrm{~h}$. Providing health care services to homeless people in EDs is a complex issue. This results from the absence of system solutions in this regard and the specificity of homelessness especially of non-institutionalized homeless people, for whom lack of insurance is characteristic as almost half of homeless patients' stays in EDs involve uninsured people. Round-the-clock access to social workers in EDs could improve the process of initiating the procedure for insuring uninsured homeless people, as well as could increase the chances of covering them with the social welfare system. The main reasons for admissions of the homeless to EDs are mental and behavioral disorders, mostly due to alcohol use, and head injuries. CT scans are the primary radiological diagnostics in homeless patients.

\section{REFERENCES}

1. Ministry of Family, Labor and Social Policy. Department of Social Assistance and Integration. [Results of the National Survey on the Number of Homeless People - 2019 edition]. [Internet]. Warsaw: The Ministry; 2019 [cited 2019 Nov 7]. Available from: https://www.gov.pl/web/rodzina/wynikiogolnopolskiego-badania-liczby-osob-bezdomnych-edycja-2019.

2. Azar KMJ, Petersen JP, Shen Z, Nasrallah C, Pesa J, LaMori J, et al. Serious Mental Illness and Health-Related Factors Associated with Regional Emergency Department Utilization. Popul Health Manag. 2020;23(6):430-7, https://doi.org/10. 1089/pop.2019.0161.

3. Doran KM, Ragins KT, Iacomacci AL, Cunningham A, Jubanyik KJ, Jenq GY. The revolving hospital door: hospital readmissions among patients who are homeless. Med Care. 2013; 51(9): 767-73, https://doi.org/10.1097/MLR.0b013e3 1829 fafbb.
4. Little GF, Watson DP. The homeless in the emergency department: a patient profile. J Accid Emerg Med. 1996; 13: 415-7, https://doi.org/10.1136/emj.13.6.415.

5. Kushel MB, Perry S, Bangsberg D, Clark R, Moss AR. Emergency department use among the homeless and marginally housed: results from a community-based study. Am J Public Health. 2002;92:778-84, https://doi.org/10.2105/ajph. 92.5.778.

6. Śledzianowski J. [Health of the homeless]. Kielce: Towarzystwo Pomocy im. św. Brata Alberta; 2006. p. 11-30. Polish.

7. Dębski M. [Health condition of the homeless]. In: Dębski M, Retowski S, editors. [The psychosocial profile of the homeless in Trójmiasto]. Gdańsk: Uniwersytet Gdański; 2008. p. 233-67. Polish.

8. Olech P, Ługowski K. [Health issues of homeless people the perspective of social welfare and health care specialists]. In: Bełdowska E, Szczypior E, Stec K, Dębski M, Browarczyk $€$, Olech P, et al, editors. [Compendium of homelessness and health]. Gdańsk: PWFB; 2006. p. 34-9. Polish.

9. Word Health Organization. International Statistical Classification of diseases and related health problems ICD-10. Vol. I. Geneva: The Organization; 2011.

10. Burak A, Kłopocka M, Wyszkowska Z. Mental and behavioral disorders in the population of homeless patients admitted to hospital emergency departments. Curr Probl Psychiatry. 2019;20(3):198-212, https://doi.org/10.2478/ cpp-2019-0013.

11. Feral-Pierssens AL, Aubry A, Truchot J, Raynal PA, Boiffier M, Hutin A, et al. Emergency Care for Homeless Patients: A French Multicenter Cohort Study. Am J Public Health. 2016; 106(5):893-8, https://doi.org/10.2105/AJPH.2015.303038.

12. Wang H, Nejtek VA, Zieger D, Robinson RD, Schrader CD, Phariss C, et al. The Role of Charity Care and Primary Care Physician Assignment on ED Use in Homeless Patients. Am J Emerg Med. 2015;33(8):1006-11, https://doi.org/10.1016/ j.ajem.2015.04.026.

13. Lombardi K, Pines JM, Mazer-Amirshahi M, Pourmand A. Findings of a national dataset analysis on the visits of 
homeless patients to US emergency departments during 2005-2015. Public Health. 2020;178(3):82-9, https://doi. org/10.1016/j.puhe.2019.09.003.

14. Mackelprang JL, Qiu Q, Rivara FP. Predictors of Emergency Department and Inpatient Readmissions among Homeless Adolescents and Young Adults, Med Care. 2015;53(12): 1010-7, https://doi.org/10.1097/MLR.0000000000000436.

15. Hammig B, Jozkowski K, Jones Ch. Injury-related Visits and Comorbid Conditions Among Homeless Persons Presenting to Emergency Departments. AEM. 2014;21(4):449-55, https://doi.org/10.1111/acem.12343.

16. Brown AJ, Goodacre SW, Cross S. Do emergency department attendances by homeless people increase in cold weather? Emerg Med J. 2010;27(7):526-9, https://doi.org/ 10.1136/emj.2009.076679.

17. Yeniocak S, Kalkan A, Sogut O, Karadana GA, Toptas M. Demographic and clinical characteristics among Turkish homeless patients presenting to the emergency department. Turk J Emerg Med. 2017;17(4):136-40, https://doi.org/10. 1016/j.tjem.2017.09.002.

18. Fazel S, Geddes JR, Kushel M. The health of homeless people in high-income countries: descriptive epidemiology, health consequences, and clinical and policy recommendations. Lancet. 2014;384(9953):1529-40, https://doi.org/10.1016/ S0140-6736(14)61132-6.

19. Beijer U, Andréasson S. Gender, hospitalization and mental disorders among homeless people compared with the general population in Stockholm. Eur J Public Health. 2010;5: 511-6, https://doi.org/10.1093/eurpub/ckq033.

20. Karaca Z, Wong HS, Mutter RL. Characteristics of homeless and non-homeless individuals using inpatient and emergency department services, 2008. In: Healthcare Cost and Utilization Project (HCUP) Statistical Briefs. [Internet]. Rockville, MD: Agency for Health Care Policy and Research; 2013 [cited 2018 May 3]. Available from: http://www.ncbi. nlm.nih.gov/books/NBK137747.

21. Beijer U, Wolf A, Fazel S. Prevalence of tuberculosis, hepatitis $\mathrm{C}$ virus, and HIV in homeless people: a systematic review and meta-analysis. Lancet Infect Dis. 2012;12:859-70. https://doi.org/10.1016/S1473-3099(12)70177-9.

22. Hwang YW, Lee YJ, Kong SY. Epidemiology and clinical outcomes of tuberculosis among homeless persons visiting emergency department in public hospital. Am J Emerg Med. 2018;36(1):164-6, https://doi.org/10.1016/j.ajem.2017. 07.049 .

23. Appleton SC, Connell DW, Singanayagam A, Bradley P, Pan D, Sanderson F, et al. Evaluation of prediagnosis emergency department presentations in patients with active tuberculosis: the role of chest radiography, risk factors and symptoms BMJ Open Respir Res. 2017;4:e000154, https:// doi.org/10.1136/bmjresp-2016-000154.

24. Geyer BC, Godwin P, Powell TJ, Moffitt MP, LoVecchio F. Patient Factors Associated with Failure to Diagnose Tuberculosis in the Emergency Department. J Emerg Med. 2013;45(5): 658-65, https://doi.org/10.1016/j.jemermed.2013.05.002.

25. Arnaud A, Chosidow O, Détrez MA, Bitar D, Huber F, Foulet F, et al. Prevalences of scabies and pediculosis corporis among homeless people in the Paris region: results from two randomized cross-sectional surveys (HYTPEAC study). Br J Dermatol. 2016;174(1):104-12, https://doi.org/ 10.1111/bjd.14226.

26. Asgary R. Cancer screening in the homeless population. Lancet Oncol. 2018;19(7):344-50, https://doi.org/10.1016/ S1470-2045(18)30200-6.

27. Chau S, Chin M, Chang J, Luecha A, Cheng E, Schlesinger J, et al. Cancer risk behaviors and screening rates among homeless adults in Los Angeles County. Cancer Epidemiol Biomarkers Prev. 2002;11:431-8.

28. Gelberg L, Lu MC, Leake BD, Andersen RM, Morgenstern H, Nyamathi AM. Homeless women: Who is really at risk for unintended pregnancy? Matern Child Health J. 2008;12: 52-60, https://doi.org/10.1007/s10995-007-0285-1.

29. Crawford DM, Trotter EC, Sittner Hartshorn KJ, Whitbeck LB. Pregnancy and mental health of young homeless women. Am J Orthopsych. 2011;81:173-83, https://doi.org/ 10.1111/j.1939-0025.2011.01086.x. 
30. Günalp M, Gülünay B, Polat O, Demirkan A, Gürler S, Akkaş $\mathrm{M}$, et al. Ionising radiation awareness among resident doctors, interns and radiographers in a university hospital emergency department. Radiol Med. 2014;119(6):440-7, https://doi.org/10.1007/s11547-013-0374-8.

31. Rodriguez RM, Fortman J, Chee C, Ng V, Poon D. Food, shelter and safety needs motivating homeless persons' visits to an urban emergency department. Ann Emerg Med. 2009; 53(5):598-602, https://doi.org/10.1016/j.annemergmed. 2008.07.046.
32. Pietrzak-Komar K. [Health portrait of the homeless on the example of the homeless from Olsztyn] Warm-Mazur Kwart Nauk, Nauki Społ. 2014;3:57-82. Polish.

33. Martell JV, Seitz RS, Harada JK, Kobayashi J, Sasaki VK, Wong C. Hospitalization in an urban homeless population: the Honolulu Urban Homeless Project. Ann Intern Med. 1992;116:299-303.

34. Holecki T, Woźniak-Holecka J, Bocionek A. [Financing of healthcare services for uninsured persons on the basis of a decision of an executive body of local government.] Pr Nauk Uniw Ekonom Wrocł. 2013;307:224-32. Polish.

This work is available in Open Access model and licensed under a Creative Commons Attribution-NonCommercial 3.0 Poland License - http://creativecommons.org/ licenses/by-nc/3.0/pl/deed.en. 